\title{
Changes in chromatin active fraction of germinating seedlings of wheat under the effect of EMI EHF
}

\author{
P.O. Vardevanyan, M.A. Parsadanyan, M.A. Shahinyan*, M.R. Darbinyan \\ Department of Biophysics, Faculty of Biology, Yerevan State University, A. Manoogian 1, Yerevan, Armenia.
}

\begin{tabular}{l}
\hline ARTICLE INFO \\
\hline Article history: \\
Received on: 10/02/2014 \\
Revised on: $14 / 03 / 2014$ \\
Accepted on: $07 / 04 / 2014$ \\
Available online: $27 / 04 / 2014$ \\
\hline
\end{tabular}

Key words: Area under the integral curve, chromatin active fraction, differential melting curve, EMI EHF, wheat dry seeds and germinating seedlings.

\begin{abstract}
The effect of electromagnetic irradiation with extremely high frequencies (EMI EHF) on chromatin active fraction of wheat germinating seedlings has been studied. In present work the first zone of saccharine gradient was investigated which is enriched with transcribing genes and comprises higher quantity of AT-sequences compared with other zones. It was shown that the effect of EMI EHF results in chromatin activation. At germination and EMI EHF effect on the differential melting curves besides the pronounced high temperature peak which is corresponded to the melting of stabilized DNA in non active chromatin content, gradually the second low temperature peak is appeared which in its turn is corresponded to the melting of destabilized DNA in active chromatin content.
\end{abstract}

\section{INTRODUCTION}

During the viability the living organisms are always exposed to the effect of different factors of the environment. Among these factors the electromagnetic irradiations (EMI) with different frequencies have a significant implication [1]. Due to the anthropogenic development, studies of EMI, the sources of which besides the natural ones are the household appliances, become important [2-4]. EMI with extremely high frequencies (EHF) acquire a special significance [5,6]. The studies of EMI EHF effect are important due to the non thermal influence on biological objects as well [1,6,7]. Interestingly the living organisms being on any organization level are exposed to the effect of EMI EHF [8-11]. There exist many works [10,12,13], where the effect of EMI EHF on different parameters of plants, particularly on intensity of both growth and metabolic processes of wheat seedlings during their germination have been investigated. It has been established that EMI EHF affect on nuclear fractions of wheat seedlings changing the value of electrokinetic potential of nuclear membranes, as well as on

\footnotetext{
* Corresponding Author

M.A. Shahinyan, Department of Biophysics, Faculty of Biology, Yerevan State University, A. Manoogian 1, Yerevan, Armenia.

E-mail: mariamsh@rambler.ru, Phone (+374 10 571061)
}

phospholipid content of nuclear subfractions. Earlier it was shown that the value of electrokinetic potential is correlated with genome functional activity [13]. It was also shown that EMI EHF influence on genetic material - DNA in vitro, moreover result in changing of its melting parameters [8]. Therefore the studies of EMI EHF effect on genome level in vivo are quite actual.

In eukaryotic cells nuclear DNA is in chromatin. The important proteins in chromatin are histone proteins - the main proteins that are responsible for DNA packing degree confined within eukaryotic nucleus [14]. It is known that chromatin is consisted of two parts - euchromatin and heterochromatin [14-16].

In present work the effect of EMI EHF on chromatin active fraction of wheat germinating seedlings has been studied.

\section{MATERIALS AND METHODS}

Experiments were carried out using Triticum aestivum $\mathrm{L}$. wheat seeds of Bezostaya 1 sort. The seeds were isolated using previously reported method [17] and placed on nourishing medium containing $0.9 \%$ agar, $1 \%$ glucose and $0.01 \%$ streptomycin in preliminary sterilized Petri dishes in dark, at $26{ }^{\circ} \mathrm{C}$ during 24 and $48 \mathrm{~h}$. The sprouting medium contains $5 \mathrm{mM}$ tris- $\mathrm{HCl}, \mathrm{pH}=7.4$; $20 \mathrm{mM} \mathrm{KCl} ; 20 \mathrm{mkg} / \mathrm{ml}$ saccharine. To obtain the experimental variants of seedlings after $24 \mathrm{~h}$ the irradiation was carried out by 
non thermal coherent EMI EHF. As an exposure source high frequency generator of EMI signals G4-141 was used with 37.50$53.57 \mathrm{GHz}$ working diapason. Irradiation frequency corresponded to $50.3 \mathrm{GHz}$ with $180 \mathrm{~mm}$ distance from conductor. The irradiation was carried out during $40 \mathrm{~min}$ with $0.64 \mathrm{~mW} / \mathrm{cm}^{2}$ power flux density. Frequency signal stability was $\pm 0.05 \%$, the distortion of output signal of frequency in generation constant regime does not exceed $6 \mathrm{MHz}$.

All procedures for obtaining of chromatin fractions were carried out according to the method described in [18]. For maximal preservation of native fractions of transcriptionally active oligonucleosome fragments of chromatin and support of their constant output, the conditions of soft hydrolysis by DNAase II (Serva) were applied. These conditions with some modifications were based on the method described in [19], the fractionation scheme of which permit obtaining the chromatin having oligonucleosome sizes, containing small amount of mononucleosome component. The conditions of partial hydrolysis applied in our procedure result in formation of $\approx 1 \%$ acid-soluble material from the whole amount of initial chromatin of dry seeds and $\approx 3 \% 24 \mathrm{~h}$ and $48 \mathrm{~h}$ germinating and irradiated seedlings.

The selection of optimal conditions of saccharine gradient was carried out on the chromatin of dry seeds and oneday seedlings (200 unit opt. dens./ml at $\lambda=260 \mathrm{~nm}$ ) with such calculation that the output of fractions from dry seeds and germinating seedlings was sufficient for their further investigation by the thermal denaturation method. The fractions obtained at chromatin centrifugation in saccharine density gradient were extracted with micropomp: the absorption was registered at $\lambda=260 \mathrm{~nm}$ on spectrophotometer Pye-Unicam SP-8-100 (England) in which the running cuvette was established $(v=3 \mathrm{ml})$. The fractions were assembled per $1.5 \mathrm{ml}$ from tube bottom.
The thermal denaturation of oligonucleosomes was carried out on spectrophotometer Pye-Unicam SP-8-100 as it is described in [18]. Before the melting the samples were dialyzed versus $0.1 \times \mathrm{SSC}$ during the night at $4^{0} \mathrm{C}$. The differential melting curves were obtained by numerical differentiation of normalized curves. The areas under the integral curves were calculated via Origin 6.0 program.

\section{RESULTS AND DISCUSSION}

It is known that the germination of isolated wheat germs is accompanied by loosening of chromatin structure which results in increasing of active fraction amount [18]. In agreement with general considerations all basic structural peculiarities of native chromatin may be investigated through the equivalent simple system which in its turn may be studied by thermal denaturation method.

In present work the first zone of saccharine gradient has been investigated which is enriched by transcribing genes and comprises higher percent of AT-sequences. The melting of chromatin fraction of dry wheat seeds was studied (fig. 1a). As it is obvious from this figure, the differential melting curve possesses one pronounced peak in the region of high temperatures which indicates that DNA in the chromatin content is mainly in non active form, highly stabilized and melted at high temperature. The melting of wheat chromatin fractions of germinating seedlings during $24 \mathrm{~h}$ and $48 \mathrm{~h}$ was carried out as well. It is obvious from fig. $1 \mathrm{~b}$ and $1 \mathrm{c}$, that at germination two peaks are revealed on the differential melting curves, moreover the height of the peak in the range of high temperatures is decreased which indicates that DNA in the chromatin fraction from non active form passes to active one and this is accompanied with DNA destabilization, that is why DNA starts melting at low temperatures.
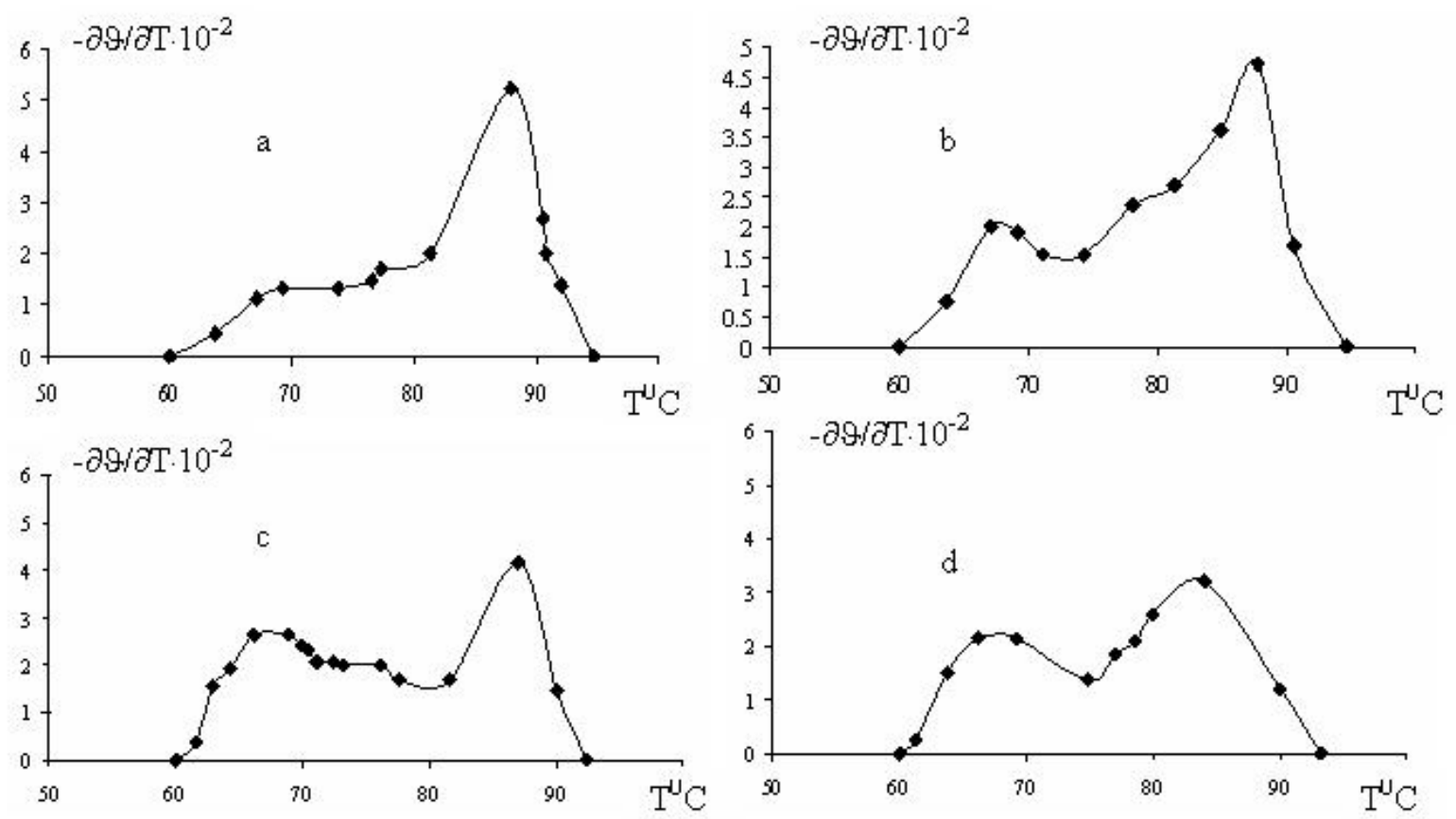

Fig 1. The differential melting curves of chromatin fraction of wheat dry seeds (a), germinating seedlings during $24 \mathrm{~h}$ (b), germinating seedlings during $48 \mathrm{~h}$ (c), germinating seedling during $24 \mathrm{~h}$ after the effect of EMI EHF (d). 
The melting of chromatin fraction of wheat germinating seedlings during $24 \mathrm{~h}$ that were exposed to the effect of EMI EHF at germination was also studied. As it is presented on fig. 1d, two peaks are revealed on the differential melting curve, which indicates that the effect of EMI EHF results in transition of DNA in the composition of chromatin fraction to active form and its melting at low temperatures.

For statement of above mentioned, the areas under the integral melting curves in different temperature intervals were determined. As it is presented on fig. $2 \mathrm{a}$, at the chromatin fraction melting of wheat dry seeds, in $60-70{ }^{\circ} \mathrm{C}$ interval the area under the integral curve is $15.19 \%$ of whole area, in $70-80{ }^{\circ} \mathrm{C}$ interval$12.8 \%$, in $80-90{ }^{\circ} \mathrm{C}-60.3 \%$, higher than $90{ }^{\circ} \mathrm{C}-11.7 \%$. These data indicate that the area under the integral curve is maximal at 80-90 ${ }^{\circ} \mathrm{C}$ which means that DNA in the chromatin fraction composition is in stabilized form, i.e. in non active form. At the germination of wheat seedlings during $24 \mathrm{~h}$ (fig. $2 \mathrm{~b}$ ) the area under the integral curve at $60-70{ }^{\circ} \mathrm{C}$ is $20.64 \%$ of the whole area, at $70-80{ }^{\circ} \mathrm{C}$ $24.92 \%$, at $80-90{ }^{\circ} \mathrm{C}-47.29 \%$ and higher than $90{ }^{\circ} \mathrm{C}-7.15 \%$. As it is obvious from the data the activation of chromatin of germinating seedlings compared to dry seeds is observed since the area under the integral curve is increased at low temperatures, i.e. DNA in the content of chromatin fraction transits to active form.

At the germination of wheat seedlings during $48 \mathrm{~h}$ (fig. 2c), the following situation is observed: at $60-70{ }^{\circ} \mathrm{C}$ the part of the area under the integral curve is $31.89 \%$, at $70-80{ }^{\circ} \mathrm{C}-31.86 \%$, at $80-90{ }^{\circ} \mathrm{C}-32.63 \%$ and higher than $90{ }^{\circ} \mathrm{C}-3.62 \%$. The area under the integral curve is increased at low temperatures; moreover the increasing is more at $60-70{ }^{\circ} \mathrm{C}$ that indicates the strong destabilization of DNA in chromatin content, i.e. chromatin is in active form.

The investigation of EMI EHF effect on the chromatin of wheat germinating seedlings during $24 \mathrm{~h}$ was also carried out. It is obvious from the data presented on fig. $2 \mathrm{~d}$, that at $60-70{ }^{\circ} \mathrm{C}$ the part of the area under the integral curve is $46.76 \%$, at $70-80{ }^{\circ} \mathrm{C}-$ $23.22 \%$, at $80-90{ }^{\circ} \mathrm{C}-23.22 \%$ and higher than $90{ }^{\circ} \mathrm{C}-6.79 \%$ respectively. As the data show, the effect of EMI EHF results in chromatin activation of wheat germinating seedlings.

Most probably this fact is connected with the binding of non histone proteins to DNA, as a result of which DNA is destabilized and melted at low temperatures - lower than pure DNA [20]. It is also possible that chromatin activation is connected with methylation of DNA itself [14]. Besides at comparison of chromatin differential melting curves from which histone $\mathrm{H} 1$ is moved off with those of total chromatin it is revealed that $\mathrm{H} 1$ histone extraction results in increasing of the content of subfractions melting at low temperature [21,22] since in this case DNA regions are appeared in the chromatin that are practically free from proteins. It was also shown that these DNA regions in chromatin unstable to thermal denaturation are enriched by ATpairs [20]. The increase of transcriptional activity of cells invokes an appearing of chromatin regions characterized by lowered melting temperature [18]. On the other hand at preparation to condensation of chromosomes in the cells stimulated to replication the stable DNA regions in the chromatin are appeared and the melting temperature significantly increases [18].

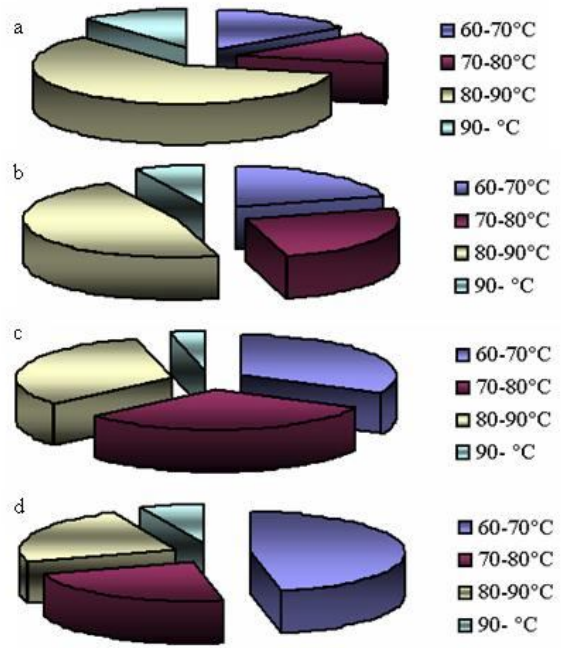

Fig 2. The part of areas under the integral curves of chromatin fractions of wheat dry seeds (a), germinating seedlings during $24 \mathrm{~h}$ (b), germinating seedlings during $48 \mathrm{~h}$ (c) and germinating seedlings during $24 \mathrm{~h}$ after the effect of EMI EHF (d).

\section{CONCLUSION}

Therefore it has been obtained that the effect of EMI EHF results in chromatin activation which is reflected on the differential melting curves of chromatin fractions. At germination and EMI EHF effect on the melting curves besides the pronounced high temperature peak corresponded to stabilized DNA in non active chromatin content, gradually the second low temperature peak is appeared corresponded to the melting of destabilized DNA in active chromatin content.

\section{REFERENCES}

1. Almeida LC. Environment, biological rhythms, depression and EM radiations. Res. Journal of Environment and Earth Sciences. 2011; 3(2):81-89.

2. Lapinsky SE, Easty AC. Electromagnetic interference in critical care. J. of Critical Care. 2006; 21:267-270.

3. Wallin MKEB, Marve T, Hakansson PK. Modern wireless telecommunication technologies and their electromagnetic compatibility with life-support equipment. Anesth. Analg. 2005; 101:1393-1400.

4. Tan KS, Hinberg I. Effects of a wireless local area network (LAN) system, a telemetry system and electrosurgical devices on medical devices in a hospital environment. Biomed. Instrum. Technol. 2000; 34:115-118.

5. Betskii OV, Devyatkov ND, Kislov VV. Millimeter waves with low intensity in medicine and biology. Biomedical radioelectronics. (In Russian). 1998; 4:13-29.

6. Betskii OV, Lebedeva NN. Contemporary presentations about the mechanisms of the effect of low intensive millimeter waves on 
biological objects. Millimeter waves in biology and medicine. (In Russian). 2001; 3:5-18.

7. Tenforde TS, Kaune WT. Interaction of extremely low frequency electric and magnetic with humans. Health Phys. 1987; 53:585606.

8. Babayan YS, Akopyan SN, Ghazaryan RS, Kalantaryan VP, Simonyan GS, Khachatryan AB, Antonyan AP, Vardevanyan PO. Some physical-chemical properties of DNA irradiated by low-energetic millimeter coherent electromagnetic waves. Biomedical technologies and radioelectronics. (In Russian). 2006; 11:64-68.

9. Kalantaryan VP, Babayan YS, Gevorgyan ES, Hakobyan SN, Antonyan AP, Vardevanyan PO. Influence of Low Intensity Coherent Electromagnetic Millimeter Radiation (EMR) on Aqua Solution of DNA. Progress in Electromagnetics Research Letters. 2010; 13:1-9.

10. Vardevanyan PO, Nerkararyan AV, Shahinyan MA. Influence of low intensity coherent electromagnetic millimeter waves on growth and peroxidase total activity of wheat germs. J. of Exp. Biol. and Agricult. Sci. 2013; 1(1):39-44.

11. Kumar V. Interaction of electromagnetic radiation with human body. Indian J. of Radio \& Space Physics. 2008; 37:131-134.

12. Vardevanyan PO, Nerkararyan AV, Shahinyan MA, Darbinyan MR. The effect of EMI EHF on electro-kinetic potential of cell nuclear membranes of wheat seedlings treated with hybberellic acid. J. of Experimental Biology and Agricultural Sciences. 2013; 1(4):223-227.

13. Nerkararyan AV, Shahinyan MA, Mikaelyan MS, Vardevanyan PO. Effect of millimeter waves with low intensity on peroxidase total activity and isoenzyme composition in cells of wheat seedling shoots. Int. J. of Scientific Res. in Environ. Sciences. 2013; 1(9):217-223.

14. Rosa S, Shaw P. Insights into chromatin structure and dynamics in plants. Biology. 2013; 2:1378-1410.
15. Avramova ZV. Heterochromatin in animals and plants. Similarities and differences. Plant Physiology. 2002; 129(1):4049.

16. Fransz P, Soppe W, Schubert I. Heterochromatin in interphase nuclei of Arabidopsis thaliana. Chromosom. Res. 2003; 11:227240.

17. Johnston FB, Stern H. Mass isolation of viable wheat embryos. Nature (London). 1957; 179:160-161.

18. Vardevanyan PO, Tiratsuyan SG, Vardevanyan AO, Boyajyan BG, Panosyan GA. Study of oligonucleosomes of wheat germinating seedlings enriched with transcriptionally active genes. Physiology of plants. (In Russian). 1995; 42:290-294.

19. Preobrajenskaya OV, Karpov VL, Nagorskaya TV, Mirzabekov AD. Structure of active chromatin at transcription. Molec. Biol. (In Russian). 1984; 18(2):8-20.

20. Defer N, Kitzis A, Kruh J, Brahms S, Brahms J. Effect on nonhistone proteins on thermal transition of chromatin and DNA. Nucl. Acids Res. 1977; 47:2293-2308.

21. Pantazis P. Fractionation of chromatin depleted of histone H1. Preparative Biochemistry, 1980; 10(5):521-528.

22. Simpson RT. Modulation of nucleosome structure by histone subtypes in sea urchin embryos. Proc. Acad. Sci. USA, Biol. Sci. 1981; 78(11):6803-6807.

\section{How to cite this article:}

P.O. Vardevanyan, M.A. Parsadanyan, M.A. Shahinyan, M.R. Darbinyan. Changes in chromatin active fraction of germinating seedlings of wheat under the effect of EMI EHF. J App Biol Biotech. 2014; 2 (02): 001-004. 